\title{
A inserção social de negros, índios e bastardos a partir de registros de óbitos (planalto paranaense na primeira metade do século XVIII) ${ }^{1}$
}

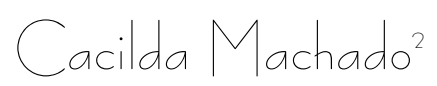

O início da colonização do planalto

Desde o século XVI os espanhóis reivindicavam direitos de posse sobre a maior parte do território que hoje faz parte do Brasil meridional, ainda assim, aquelas terras eram sistematicamente percorridas também por outros europeus, especialmente portugueses, organizados em expedições exploradoras e preadoras. ${ }^{3}$ Mas a ocupação portuguesa tornou-se mais efetiva somente no final daquele século, quando foram encontrados os primeiros vestígios de faíscas de ouro no litoral do atual Estado do Paraná. Desde então, populações provenientes de Cananéia, São Vicente, Santos, São Paulo

\footnotetext{
${ }^{1}$ Este artigo é um produto parcial de uma pesquisa financiada pela FAPERJ.

${ }^{2}$ Doutora em História Social pela Universidade Federal do Rio de Janeiro, professora da ESS-UFRJ.

${ }^{3}$ Apenas para a área que hoje forma o Estado do Paraná, existem registros de pelo menos dez grandes expedições no século XVI, saindo ora do Atlântico ora da região platina. Dentre elas a expedição comandada por Aleixo Garcia (1516), Francisco de Chaves e Pero Lobo (1530), Álvaro Nuñez Cabeza de Vaca (1541), Ulrich Schmidel (1553), Hans Staden (1549), Cristobal Saavedra (1551), Hernando Salazar (1552), Ruy Diaz Melgarejo (1554) e Martinez de Irala (1553). CARDOSO, Jaime Antonio; WESTPHALEN, Cecília Maria. Atlas histórico do Paraná. $2^{\mathrm{a}}$. ed. Curitiba: Editora do Chain, 1986. p. 24. 
A inserção social de negros, indíos e bastardos a partir de registros de óbitos...

e Rio de Janeiro começaram a estabelecer sítios na região, utilizando o trabalho de índios - do litoral, ou apresados no interior - e mais tarde, também de negros escravizados.

A primeira povoação foi Paranaguá, originada na ilha da Cotinga, em 1617, e elevada a categoria de vila em 1649. Em 1656, esta vila tornou-se centro da recém-criada Capitania de Nossa Senhora do Rosário de Paranaguá, subordinada ao Rio de Janeiro. Ao longo do século XVII os mineradores ultrapassaram a Serra do Mar e, em busca do ouro, exploraram as terras altas do interior e formaram os primeiros núcleos populacionais no planalto: as povoações de Nossa Senhora da Luz dos Pinhais (Curitiba) - freguesia de Paranaguá desde 1654, distrito desde 1660 e elevada a categoria de vila em 1693 - e São José e Bom Jesus dos Perdões (São José dos Pinhais), na região contígua.

A partir do inicio do XVIII o ouro das Minas Gerais eclipsou a modesta produção paranaense que, no entanto, existiu pelo menos até meados do século XVIII. Em 1711, a região passou à condição de comarca da Capitania de São Paulo e em 1735 a casa de fundição de Paranaguá foi definitivamente fechada. ${ }^{4}$ No entanto, mesmo antes do declínio da economia aurifera já se desenvolvia alguma agricultura e pecuária no planalto. E na medida em que exauria o ouro, os moradores intensificaram a produção de alimentos, a criação de gado, e iniciaram o envolvimento no tropeirismo, transporte de animais do sul para Sorocaba. Já em 1721, quando visitou a região, o Ouvidor Pardinho escreveu ao rei informando, dentre outras coisas, sobre as potencialidades econômicas do planalto:

Dizem aqueles moradores [de Curitiba], que têm penetrado o sertão para o poente, que todo é de campos com seus capões e restingas de matos, com boas águas e férteis para currais e criações, nos quais se poderão fazer grandes fazendas se para eles se alargarem os gados: que o gentio é muito pouco por ele porque apenas se acham alguns pequenos lotes. Os mesmos campos vão correndo pelo pé dos matos da Serra de Pernam-

${ }^{4}$ WACHOWICZ, Ruy C. História do Paraná. 6 ed., Curitiba: Editora Gráfica Vicentina, 1988, p. 57. 
piacaba; e alguns dizem ser fácil abrir para eles caminho da vila de Laguna, donde se lhe podem introduzir gados, que se conduzam e tragam pelas praias do Rio Grande de São Pedro, com que brevemente se estabelecerão neles grandes fazendas de currais. ${ }^{5}$

Porém, na primeira metade do XVIII o planalto ainda não havia construído sua pujança econômica. A nova atividade estava apenas começando e somente a partir da segunda metade do século XVIII e início do XIX multiplicaram-se as fazendas de criação e de invernagem nos chamados Campos Gerais. Ao longo do Caminho do Viamão (que ligava o Continente do Sul a Sorocaba), os lugares de pouso e currais de descanso ou invernadas de gado iriam dar origem a novas povoações. ${ }^{6}$ Neste contexto, a antiga freguesia de São José dos Pinhais foi institucionalizada em 1757, e foram criadas as de Sant'Anna do Iapó (1760) - alçada à condição de vila em 1789, sob o nome de Vila Nova de Castro - e a de Santo Antonio da Lapa (1769), elevada à Vila Nova do Príncipe em $1806 .^{7}$

A carta e os provimentos de Ouvidor Rafael Pardinho também nos permitem conhecer aspectos relativos à vida dos moradores das terras paranaenses em princípios do XVIII. Segundo seu testemunho, em 1721, haveria, em Paranaguá, 300 casais e mais de 2000 pessoas de confissão. O ouvidor nos informa que "o comum dos homens" vivia da pesca e da lavoura de mandioca, de que se fazia farinha. Os moradores mantinham contatos permanentes com outras regiões dos domínios portugueses na América, pois muitas embarcações ali chegavam para levar a farinha para as vilas de Cananéia, Santos, Rio de Janeiro e, alguns anos, também para a Bahia. Já as povoações do planalto (Curitiba e São José), Pardinho

\footnotetext{
${ }^{5}$ Carta do ouvidor Rafael Pires Pardinho ao rei D. João V, 30 de agosto de 1721. Revista Monumenta, vol. 3, n.10. Curitiba: Aos Quatro Ventos, Inverno de 2000, p. 22 e 23.

${ }^{6}$ MARTINS, Romário. História do Paraná. Curitiba: Travessa dos Editores, 1995, p. 524.

${ }^{7}$ TRINDADE, Etelvina \& ANDREAZZA, Maria Luiza. Cultura e Educação no Paraná. Curitiba: SEED, 2001, p. 5 e 6. 
A inserção social de negros, indíos e bastardos a partir de registros de óbitos...

calculou que tinham, juntas, 200 casais e mais 1400 pessoas de confissão. ${ }^{8}$

Embora ao longo do século XVII e XVIII grandes sesmarias tenham sido distribuídas para os povoadores mais poderosos, os documentos sugerem que no planalto a vida corria sob condições muito distintas daquelas encontradas nas regiões canavieiras dos domínios portugueses na América. A vila de Curitiba possuía somente casas de pau a pique cobertas de telhas e uma igreja de pedra e barro, sugerindo o predomínio de moradias com interiores modestos, poucos cômodos, onde conviviam familiares, os escravos e agregados. O chão, de terra batida, era cercado por paredes de barro. A raridade da mobília - baús, bancos e redes - é outra evidência da rusticidade com que viviam os homens livres, qual fosse o estrato social, especialmente nos primeiros tempos. ${ }^{9}$

Em sua visita, Pardinho estabeleceu que o termo da vila de Curitiba fosse, a leste, do pico da Serra para cima, o Rio Itararé ao norte, meio do caminho entre Curitiba e Sorocaba, e a oeste o sertão ainda inexplorado. ${ }^{10} \mathrm{O}$ ouvidor também mandou organizar novas eleições de juízes ordinários, vereadores e procuradores; regulamentou a escolha e a nomeação de postos militares (capitães-mores, sargentos, capitães de ordenança); determinou a forma de se fazerem inventários e registrar os testamentos, bem como da escrita contábil e dos atos das câmaras municipais, definindo as ocupações e responsabilidades dos escrivães e tabeliães. ${ }^{11}$ Seus provimentos visavam, ainda, adequar comportamentos dos moradores das vilas, como a obrigação de comparecer às

\footnotetext{
${ }^{8}$ Carta do ouvidor Rafael Pires Pardinho ao rei D. João V...p. 22 e 24. Para informar o número de moradores, Pardinho utilizou os róis de confessados das paróquias; ou seja, uma parcela da população não foi computada - os que não recebiam comunhão (crianças, em geral).

9 TRINDADE, Etelvina \& ANDREAZZA, Maria Luiza. Op. Cit, p. 5.

${ }^{10}$ Carta do ouvidor ... p. 21 e 22.

${ }^{11}$ SANTOS, Antonio Cesar de A. e PEREIRA, Magnus Roberto de Mello. Para o bom regime da república: ouvidores e câmaras municipais no Brasil colonial. In: Monumenta, vol.3, número 10, Curitiba: Aos Quatros Ventos, inverno de 2000, p. 12 .
} 
funções e festas religiosas e não portar "armas proibidas", entre outros. ${ }^{12}$

O empenho do Pardinho em prover os moradores de normas para o estabelecimento de um governo conforme aos interesses da Coroa foi o contraponto de sua avaliação de que "até agora se governaram, mas com tantos abusos, como se pode presumir de uma remota terra, e aonde não chegou Ministro algum". ${ }^{13}$ Contra um desses abusos ele ordenou

que os juizes e oficiais da Câmara pelo que lhes toca proíbam que nenhuma pessoa entre pelo sertão a correr o gentio para os obrigarem a seu serviço, por ser contra as Leis expressas de Sua Majestade, (...) que os juízes não mandem avaliar os carijós e seus descendentes, que forem da administração dos defuntos, como por repetidas leis se tem declarado pois sendo estes por elas libertos não admitem valor e nem estimação. ${ }^{14}$

O ouvidor estava se referindo ao "costume" dos moradores do planalto paranaense (assim como na maior parte da capitania de São Paulo), de escravizar indigenas, a despeito da existência de legislação contrária. Como administradores particulares dos índios - considerados incapazes de administrarem a si mesmos -, "os colonos se apropriaram do direito de exercer pleno controle sobre a pessoa e propriedade dos mesmos sem que isso fosse caracterizado juridicamente como escravidão", ${ }^{15}$ embora não impedisse que os administrados fossem arrolados em inventários e entrassem nas partilhas, ou que fossem vendidos.

Para se ter uma idéia da importância dessa mão-deobra na região, vale lembrar os números encontrados por Stuart Schwartz, em seu estudo sobre compadrio de escravos em Curitiba. Esse autor menciona que entre 1685 e 1709 era irrelevante o número de negros batizados na vila, e que só em 1740 africanos e afro-brasileiros batizados finalmente

\footnotetext{
${ }^{12}$ Idem, p. 14.

${ }^{13}$ Carta do ouvidor ... p. 23.

${ }^{14}$ Provimentos do ouvidor Rafael Pires Pardinho. Revista Monumenta, vol. 3, n.10. Curitiba: Aos Quatro Ventos, Inverno de 2000, p. 51 e 65.

${ }^{15}$ MONTEIRO, John Manuel. Negros da Terra. Índios e bandeirantes nas origens de São Paulo. São Paulo: Companhia das Letras, 1994, p. 137.
} 
excederam em número aos índios. ${ }^{16}$ Desde os primórdios da colonização, portanto, a mão-de-obra servil do Paraná era formada tanto pelos "administrados" indígenas, como por africanos ou crioulos. Cativos de origens e histórias muito heterogêneas eram reunidos num mesmo plantel, respondendo a um mesmo senhor, dividindo as tarefas da labuta diária. Um exemplo é o testamento aberto em 1722, de Isabel Fernandes da Rocha, moradora de São José dos Pinhais. Nele foram declarados dezoito "servos",

a saber, inferiores de velhice Balthazar, Breutis escrava, [ileg.], Severina, Rufina Pascoa, todos carijós, pessoas de serviço, Anna mulata escrava, Lourenço mulato, Manoel mina, Antonio Tobe, Esmeria carijó; duas raparigas de dez anos de idade pouco mais ou menos por nome Barbara mulata, Narciza carijó, dois rapazes de campanha de sete para oito anos chamados [ileg.]. Outro de idade de seis anos chamado Salvador, duas crianças mulatas por nomes Angela e Clara escravas, mais um rapaz chamado João escravo."17

Quase não existem fontes para o estudo dos negros e indios que viveram no planalto paranaense até a metade do século XVIII, pois em geral a documentação que cobre esse período diz mais da elite da governança. ${ }^{18}$ Como as listas nominativas de habitantes começaram a ser produzidas somente a partir de $1765,{ }^{19}$ para conhecer o processo de

${ }^{16}$ SCHWARTZ, Stuart. Escravos, Roceiros e Rebeldes. Bauru (SP): Edusc, 2001, p. 218.

${ }^{17}$ Processos de Auto de contas, 1727, cópias do CEDOPE-UFPR, originais no Arquivo Dom Leopoldo Duarte. Cúria Metropolitana de São Paulo.

18 Por exemplo: PEREIRA, M. R. M. \& BORGES, J. N. Tudo consiste em dividas, em créditos e em contas: Relações de crédito no Brasil colônia; Curitiba na primeira metade do século XVIII. Revista de História (USP), v. 162, p. 105-129, 2010; PEREIRA, M. R. M. \& SANTOS, Antonio Cesar de Almeida. Para o bom regime da república; ouvidores e câmaras municipais no Brasil colonial. Monumenta, Curitiba, v. 3, n. 10, p. 1-19, 2001; PEREIRA, M. R. M. (Org.). Plano para sustentar a posse da parte meridional da América portuguesa (1772). Curitiba: Aos Quatro Ventos, 2003; PEREIRA, M. R. M. (Org.) ; NICOLAZZI JR, N. F. (Org.) . Audiências e correições dos almotacés; Curitiba, 1737 a 1828. Curitiba: Aos Quatro Ventos, 2003; STANCZYK FILHO, Milton. A luz do cabedal: acumular e transmitir bens nos sertões de Curitiba (1695-1805). Dissertação de mestrado, Curitiba: UFPR, 2005.

${ }^{19}$ As listas nominativas são censos populacionais efetuados de maneira mais ou menos sistemática especialmente nas regiões paulista e mineira, entre 1765 e 1850. Até o final do XVIII tinham fins eminentemente militares, com vistas ao 
inserção social de escravos, administrados e livres de cor no período inicial da colonização resta ao pesquisador recorrer principalmente aos registros paroquiais de batismos, casamentos e óbitos, os quais trazem dados vitais da população de Curitiba, mas também das freguesias e arraiais do planalto, que à época eram servidos apenas por capelas. Nesse artigo faço uso dessas fontes, mais especificamente dos registros de óbitos, buscando caracterizar esses grupos, de modo a resgatar alguns aspectos da inserção social deles.

\section{Negros, indios e bastardos na composição populacional}

A inexistência de estatísticas confiáveis não impede que se possa estimar o peso percentual dos diferentes grupos populacionais do planalto durante a primeira metade do século XVIII. No primeiro livro de óbitos da Paróquia de Nossa Senhora da Luz dos Pinhais, que cobre o periodo entre 1731 e 1769 , consta um total de 1026 registros, sendo que 449 deles estão na parte do livro reservada aos brancos e 577 na parte reservada aos escravos, administrados, pretos e bastardos. Os registros desses últimos começam em meados de 1731 e terminam em 1769, enquanto os de brancos iniciam em 1732 e encerram em setembro de $1762 .{ }^{20}$

\footnotetext{
recrutamento para os conflitos do Sul, e daí os sub-registros de homens e a simples contagem do total dos escravos. De 1798 a 1822 é a fase de organização das listas como censos, quando se queria conhecer a composição da população e a producão agrícola local, numa tentativa de melhor desenvolver, povoar e defender o território. De 1823 a 850 é a fase de desorganização dos trabalhos. Procurouse seguir os modelos anteriores, e até introduzir modificações, mas começam a ser feitas a espaços irregulares e por fim extinguiram-se. BACELLAR, Carlos. Os Senhores da Terra: familia e sistema sucessório entre os senhores de engenho do Oeste Paulista (1765-1855). Campinas: CMU/Unicamp, 1997, p. 33-34.

${ }^{20}$ As Constituições Primeiras do Arcebispado da Bahia, de 1707, previa em seu Livro Quatro que em todas as igrejas paroquiais haveria um livro de assentos com o nome dos defuntos. As demais informações constantes neste documento são: a data do falecimento, nome de seu cônjuge e/ou de seus pais, freguesia de origem, idade, os sacramentos recebidos, local de sepultamento, se deixou testamento, seus legados pios ou se era pobre, etc. Nem sempre constavam todas estas informações ou às vezes constavam informações suplementares. A diferença devia-se ao cuidado e maior observação do pároco ou coadjutor e à época. Alguns dados, como a cor, condição de legitimidade ou idade eram recorrentes em algumas 
A maior parte dos registros refere-se aos sepultamentos ocorridos na Igreja matriz de Nossa Senhora da Luz, de Curitiba, mas alguns foram realizados na Capela de Nossa Senhora do Terço (também em Curitiba, onde a partir de 1752 passou a funcionar a Irmandade da Ordem Terceira de São Francisco das Chagas), e nas capelas rurais do planalto: Bom Jesus dos Perdões (em São José dos Pinhais), Nossa Senhora da Conceição do Tamanduá (na Fazenda do Tamanduá, do lendário Capitão povoador dos Campos Gerais, Antonio Luiz Tigre, mais tarde transferida para Palmeira), Santa Bárbara do Pitangui (onde mais tarde foi fundada Ponta Grossa) e Santo Antonio do Capão Alto (na região onde foi fundada posteriormente a vila Castro). Outros registros referem-se a sepultamento de ossos na Igreja matriz, vindos por vezes de muito longe: são 13 brancos, 13 escravos, 5 bastardos e 3 administrados cujos restos mortais foram transferidos dos Campos Gerais, dos Campos dos Ambrósios, do Arraial Grande, da Borda do Campo, do Caminho do Viamão ou simplesmente "do sertão".

Tomando apenas os registros de óbitos do período 1732-1761, têm-se 437 brancos e 388 não brancos, contabilizando um total de 825 pessoas, ou seja, do total de pessoas registradas, $47 \%$ foram identificadas como nãobrancas. Esse indice mais ou menos coincide com o dado fornecido por Octavio Ianni, em As metamorfoses do escravo. Nesse livro o autor cita a estimativa do Capitão-general de São Paulo, Dom Luis Antonio de Souza Botelho e Mourão o Morgado de Matheus -, que em 1767 calculou em 50\% a proporção de escravos entre os habitantes da região. Esse número parece exagerado, e o próprio Ianni não confiou na contagem, deduzindo que o Capitão-general considerou todos os negros, índios e mestiços como escravos. ${ }^{21}$

A partir dos óbitos também foi possível encontrar indícios a respeito da composição sexo-etária dos grupos. Nova-

épocas e somem em outras. (LOTT, Mirian Moura. Constituições Primeiras do Arcebispado da Bahia. In: Anais do VII Simpósio da Associação Brasileira de História das Religiões. Belo Horizonte, PUC-MG, 2005).

${ }^{21}$ IANNI, Octavio. As metamorfoses do escravo. 2a . Ed, São Paulo: Hucitec/ Curitiba:Scientia et Labor, 1988, p. 70. 
mente tomando o total de mortes registradas no livro 1 (isto é, de 1731 até 1769 ), do total de brancos, $37,8 \%$ tinham até 14 anos. Para os não-brancos esse índice é de 33,9\%. Na amostra dos adultos (660 registros), foram contados 279 de brancos e 381 de não-brancos. Entre os registrados como brancos, $54,5 \%$ eram homens; entre os não-brancos esse percentual era de 50,9\%. Embora as crianças provavelmente estejam super-representadas na fonte, em função das altas taxas de mortalidade infantil no passado, este quadro de equilíbrio sexual e de certa equivalência entre os percentuais de crianças dos grupos branco e não branco é coerente com o que se encontra para o período posterior no planalto (tabela 1), a partir dos dados dos mapas de habitantes.

Tabela 1: Comparativo entre os \% de homens e crianças nas populações branca e não branca

Planalto Paranaense - 1731-1824

\begin{tabular}{l|c|c|c}
\hline & $1731-1769^{*}$ & $1798^{* *}$ & $1824^{* *}$ \\
\hline \% de homens brancos & 54,5 & 48,6 & 49,0 \\
\hline$\%$ de homens não brancos & 50,9 & 49,1 & 47,5 \\
\hline & & & \\
\hline$\%$ de crianças brancas & 37,8 & 35,9 & 37,2 \\
\hline$\%$ de crianças não brancas & 33,9 & 34,0 & 33,4 \\
\hline
\end{tabular}

Fontes: *Registros de Óbitos da Paróquia de Nossa Senhora da Luz dos Pinhais de Curitiba. Originais: AESP; ** COSTA, Iraci de Nero \& GUTIÉRREZ, Horácio. Paraná. Mapas de Habitantes 1798-1830. Săo Paulo: IPE-USP, 1985, passim. ${ }^{22}$

Tal coerência sugere, ainda, que os registros de óbitos - fonte em geral desacreditada devido ao recorrente subregistro - podem funcionar bem para esse tipo de estimativa sobre o período pré-estatístico, até porque aqueles sub-registros deviam afetar todos os estratos populacionais e, ao menos no que diz respeito ao locus em estudo, nada indica que à época houvesse diferenças substantivas nos indices de mortalidade de brancos e não-brancos.

Pode haver imprecisão quanto à verdadeira condição jurídica de alguns administrados nos livros de óbitos, pois

${ }^{22}$ Costa e Gutiérrez baseiam suas estatisticas nas listas nominativas de habitantes, e o percentual de crianças referem-se as pessoas com até 10 anos. 
muitos senhores e párocos registravam indígenas como cativos, especialmente no início do período aqui observado. Mas aceitando-se as quantidades tal como foram calculadas aqui, e analisando suas variações ao longo do tempo (tabela 2), observa-se a redução da população escrava e administrada e o incremento significativo do grupo de forros e livres de origem africana e indígena.

Tabela 2: Distribuição da população por cor e condição

Planalto paranaense (1732-1761)

\begin{tabular}{c|c|c|c|c|c|c|c|c|c|c}
\hline \multirow{2}{*}{ Período } & \multicolumn{2}{|c|}{ Brancos } & \multicolumn{2}{c|}{ Escravos } & \multicolumn{2}{c|}{ Administrados } & \multicolumn{2}{c|}{ Livres não-br } & \multicolumn{2}{c}{ TOTAL } \\
\cline { 2 - 11 } & $\#$ & $\%$ & $\#$ & $\%$ & $\#$ & $\%$ & $\#$ & $\%$ & $\#$ & $\%$ \\
\hline $1732-1741$ & 110 & 55,0 & 48 & 24,0 & 37 & 18,5 & 05 & 2,5 & 200 & 100,0 \\
\hline $1742-1751$ & 129 & 55,4 & 45 & 19,3 & 43 & 18,4 & 16 & 6,9 & 233 & 100,0 \\
\hline $1752-1761$ & 198 & 50,6 & 62 & 15,9 & 45 & 11,5 & 86 & 22,0 & 391 & 100,0 \\
\hline
\end{tabular}

Fonte: Registros de óbitos da Paróquia de Nossa Senhora da Luz dos Pinhais.

Tal mudança parece ser o início de um processo que se mantém até o século XIX, época em que o peso percentual médio da população escrava do Planalto cai para a faixa dos 15 a 20\%, sendo em geral mais baixo na região de Curitiba e São José, onde a criação e a agricultura de alimentos em sítios familiares se consolidaram, e mais alto a oeste, nos Campos Gerais, onde predominavam as fazendas de criação e invernagem de gado: em Curitiba, o percentual de escravos era de $18 \%$ em 1798, passa a $17 \%$ em 1810 e a $12 \%$ em 1824. Em Castro, por exemplo, nos mesmos anos, esses percentuais são de $22 \%, 22 \%$ e $27 \%{ }^{23}$

Os registros de óbitos nos dão, ainda, uma idéia acerca da posse de escravos (e de administrados) na primeira metade do XVIII. Neles encontrei a indicação de 158 senhores, sendo que 82 deles registraram somente a morte de escravos, 47 somente de administrados, e 29 registraram escravos e administrados. Pelos dados da tabela 3 se deduz uma grande maioria de pequenos proprietários, com uma média de 2,2

${ }^{23}$ COSTA, Iraci de Nero \& GUTIÉRREZ, Horácio. Op. cit, passim. 
escravos e/ou administrados por escravista, sendo um a moda. O primeiro resultado está abaixo do que se encontra para as primeiras décadas do XIX, quando a região vivia melhores dias, do ponto de vista econômico: em Curitiba, no ano de 1804 , os escravistas tinham em média 5,3 cativos, sendo a moda um cativo. Em 1824 a média era de quatro, e um cativo a moda. ${ }^{24}$ De todo modo, esse e os demais índices sugerem que, na área de Curitiba, a formação de uma sociedade de pequenos escravistas e com muitos brancos e bastardos pobres sem escravos vivendo de forma autônoma remonta a pelo menos meados do XVIII.

Tabela 3: Estrutura de posse de escravos e administrados.

Planalto Paranaense, 1731-1769

\begin{tabular}{c|c|c|c|c|c|c}
\hline \multirow{2}{*}{$\begin{array}{c}\text { Ta ma n ho } \\
\text { do plantel }\end{array}$} & $\begin{array}{c}\text { Proprietários de } \\
\text { escravos }\end{array}$ & \multicolumn{2}{c|}{$\begin{array}{c}\text { Proprietários de } \\
\text { administrados }\end{array}$} & \multicolumn{2}{c}{$\begin{array}{c}\text { Prop. escravos e/ } \\
\text { ou administrados }\end{array}$} \\
\cline { 2 - 7 } & $\#$ & $\%$ & $\#$ & $\%$ & $\#$ & $\%$ \\
\hline 1 a 4 & 103 & 92,8 & 74 & 94,9 & 143 & 91,1 \\
\hline 5 a 8 & 05 & 4,5 & 04 & 5,1 & 11 & 7,0 \\
\hline 9 ou + & 03 & 2,7 & - & - & 03 & 1,9 \\
\hline Total & 111 & 100,0 & 78 & 100,0 & 157 & 100,0 \\
\hline
\end{tabular}

Fonte: Registros de óbitos da Paróquia de Nossa Senhora da Luz dos Pinhais.

A tabela 4 traz os dados sobre a variação temporal da composição interna da população não-branca, os quais se estendem até 1769 . Por ela é possivel observar que, no início do período, $95 \%$ da população não-branca falecida no planalto era composta por escravos e administrados, e que na década 1762-1769 esse percentual havia caído para apenas $34,5 \%$. Tal decréscimo foi particularmente substantivo a partir dos anos de 1750, e se deveu ao descenso percentual de escravos, porém, mais especialmente, a redução drástica da população administrada.

${ }^{24}$ PENA, Eduardo Spiller. O Jogo da Face. A astúcia escrava frente aos senhores e à lei na Curitiba Provincial. Curitiba: Aos Quatro Ventos, 1999, p. 30. 
A inserção social de negros, indíos e bastardos a partir de registros de óbitos...

Tabela 4: Escravos, administrados e livres no conjunto da população não-branca

Paróquia de Nossa Senhora da Luz dos Pinhais de Curitiba (1731-1769)

\begin{tabular}{c|c|c|c|c|c|c|c|c}
\hline \multirow{2}{*}{ Período } & \multicolumn{2}{|c|}{ Escravos } & \multicolumn{2}{c|}{ Administrados } & \multicolumn{2}{c}{ Livres não-br } & \multicolumn{2}{c}{ TOTAL } \\
\cline { 2 - 9 } & $\#$ & $\%$ & $\#$ & $\%$ & $\#$ & $\%$ & $\#$ & $\%$ \\
\hline $1731-1741$ & 58 & 58,0 & 37 & 37,0 & 05 & 5,0 & 100 & 100,0 \\
\hline $1742-1751$ & 45 & 43,3 & 43 & 41,3 & 16 & 15,4 & 104 & 100,0 \\
\hline $1752-1761$ & 62 & 32,1 & 45 & 23,3 & 86 & 44,6 & 193 & 100,0 \\
\hline $1762-1769$ & 51 & 29,3 & 09 & 5,2 & 114 & 65,5 & 174 & 100,0 \\
\hline
\end{tabular}

Fonte: Registros de óbitos da Paróquia de Nossa Senhora da Luz dos Pinhais.Total de registros legiveis: 571

Ainda que os dados da década 1761-1769 se refiram apenas à vila de Curitiba (por então já funcionavam paróquias independentes em São José dos Pinhais e nos Campos Gerais), nada indica que a mudança se deva a uma concentração excepcional de administrados na área especializada em criação de invernagem do gado. Os dados sugerem até mesmo o contrário, pois dentre os óbitos anteriores (isto é, de 1731 a 1761) apenas um administrado foi sepultado na capela de Nossa Senhora da Conceição do Tamanduá, um administrado foi sepultado na Capela Bom Jesus dos Perdões de São José e os demais 122 na Igreja de Nossa Senhora da Luz dos Pinhais de Curitiba. E dos sepultamentos de ossos vindos dos Campos e do Caminho do Viamão, como se viu, apenas três eram de administrados.

A meu ver, o crescimento substantivo da população livre não-branca a partir de 1750 se refere, e em parte significativa, à crescente impossibilidade da elite local de continuar mantendo sob seu domínio a população indígena, o que nos dá uma idéia do quanto os esforços da coroa, durante a primeira metade de XVIII, para impedir a continuação do apresamento e a servidão indígena afetaram aquele domínio senhorial. ${ }^{25}$ Conquistada a autonomia efetiva, aqueles indios

${ }^{25}$ A primeira metade do século XVIII foi, na região paulista, período marcado pelo intenso conflito entre um poder local, de caráter privado, assentado numa tradição de conquista e de mando sobre a população indigena e mestiça, e um 
passaram a engrossar as estatísticas referentes ao grupo dos bastardos livres. De fato, no planalto paranaense, entre 1798 e 1824 , cerca de 50 ou $60 \%$ da população não-branca era formada por livres (e em torno de $30 \%$ da população livre não era branca). ${ }^{26}$

Mas não apenas. Há que se considerar a possibilidade de que outra parte dos livres não-brancos fossem forros e negros ou mulatos livres migrados de outras localidades. Porém, nos registros de óbitos há poucas informações. Para 22 dos não-brancos livres, consta serem forros, mas na maior parte desses registros foi acrescentada a informação de que teriam sido administrados. Alguns poucos foram qualificados como mulatos ou pretos forros ou livres, porém consta a origem de apenas sete deles: dois eram do Rio de Janeiro, um de Sorocaba, um de Itu, um de Paranaguá, outro de São Paulo e um de Minas Gerais.

Nos registros de casamentos da época, os livres não brancos que eram migrantes procediam em geral do sul (Ilha de Santa Catarina, Rio de São Francisco, Laguna), de outras localidades da capitania de São Paulo (de Paranaguá e das vilas de São Paulo, Santos, Sorocaba, Minas do Paranapanema, Jundiaí, Santo Amaro, Taubaté, Guaratinguetá, Guarulhos, Pindamonhangaba, Cotia, Mogi das Cruzes, Mogimirim), e alguns do Rio de Janeiro e de Minas Gerais (Vila Rica, Mariana, Ouro Branco, Guarapiranga). Os brancos migrantes em geral procediam dessas mesmas regiões, e uma parte deles veio de Portugal e Ilhas. Essas informações sugerem a existência, principalmente a partir de 1750 , de uma fronteira agrária receptiva também a homens e mulheres recém-saídos do cativeiro, fenômeno que no Paraná aparentemente ganha maiores proporções no século XIX. ${ }^{27}$ Esta hipótese ganha

\footnotetext{
poder régio que buscava subordinar aquele poder à autoridade da administração colonial. MONTEIRO, John M. Tupis, Tapuias e Historiadores: estudos de história indigena e do indigenismo. Tese de Livre Docência. Campinas: UNICAMP, 2001, p. 80.

${ }^{26}$ COSTA E GUTIERREZ. Op. Cit, passim.

${ }^{27}$ Sobre essa questão ver: LIMA, Carlos A. M. Sertanejos e pessoas republicanas. Livres de cor em Castro e Guaratuba (1801-1835). In: Revista Estudos AfroAsiáticos, 2002. 
força quando se atenta que, no período - ainda acreditando nos registros de óbitos como índice razoável para ter uma idéia do conjunto total da população -, a população não branca cresceu $136 \%$, enquanto o crescimento da população branca foi de apenas $80 \%$.

\section{O lugar social dos não-brancos}

Ao longo do processo de incremento acentuado do grupo de livres não-brancos, os qualificativos mais freqüentes para se referirem a eles mudaram: no registro de óbitos, os escravos e administrados são em geral qualificados pela origem (mina, crioulo, gentio da terra, carijó, etc.), apenas nas duas últimas décadas aparecem administrados qualificados como bastardos. Quanto aos livres, a indicação de mistura aparece desde o inicio (mulatos e bastardos), sendo tais qualificativos muito mais recorrentes para este grupo: 21 pessoas foram identificadas como índios, forros, pretos, carijós; e 40 como bastardos (principalmente) e/ou mulatos. A própria forma como o vigário intitulou os óbitos anualmente sugere essas mudanças. Até 1763 ele abria o ano informando que se tratava dos falecimentos de escravos e servos, ou de pretos e servos, ou pretos e carijós, ou ainda escravos e administrados. A partir de 1764, passa a incluir o qualificativo "bastardo" (escravos e bastardos; pretos e bastardos). ${ }^{28}$

Em resumo, ainda que os dados sejam restritos, pode-se inferir a tendência, conforme a população cativa e administrada se reduz drasticamente, de igualar pessoas de

\footnotetext{
${ }^{28}$ Em um artigo em que faz uma análise qualitativa do primeiro censo populacional do planalto, realizado em 1765, com fins militares, Maria Luiza Andreazza observou uma visão mais uniforme da população, sem a variedade das cores que hierarquizavam o homem colonial, aparecendo com nitidez apenas a distinção entre livres e escravos. (ANDREAZZA, Maria Luiza. El papel de los censos en La producción de las categorias sociales y espaciales de las colonias americanas. In: Poblaciones históricas: fuentes, métodos y lineas de investigacion. Rio de Janeiro: ALAP, 2009). Mas talvez isso se deva apenas à natureza da fonte (no que tange ao alistamento militar talvez importasse menos a cor ou a origem, e mais o número de armas), ou quem sabe a igreja era muito mais ciosa das hierarquias.
} 
origens diversas a partir do uso de um qualificativo (ou desqualificativo) de "impureza": uma forma de lembrar que o esforço de conquista de liberdade e autonomia deles, e o fato de conviverem com brancos em geral tão pobres quanto eles, não deveria obliterar essa marca de distinção social. Tal quadro guarda certo nexo com o que obtive em estudo sobre essa mesma região, porém referente a passagem do XVIII para o $\mathrm{XIX},{ }^{29}$ ainda que por então o qualificativo generalizante mais recorrente fosse "pardo". Conforme já observou Hebe Mattos, durante o século XIX, no Brasil,

a emergência de uma população livre de ascendência africana - não necessariamente mestiça, mas necessariamente dissociada, já por algumas gerações, da experiência mais direta do cativeiro - consolidou a categoria 'pardo livre' como condição lingüística para expressar a nova realidade, sem que recaísse sobre ela o estigma da escravidão, mas também sem que se perdesse a memória dela e das restrições civis que implicava. ${ }^{30}$

Essa homogeneização de certa forma também se expressa na descrição do pároco sobre a situação econômica dos falecidos. Considerei apenas os óbitos dos não-brancos maiores de 15 anos (381 óbitos) e, deles, retirei os escravos e os administrados, restando 131 registros. Desse último total, em 85 não há qualquer informação sobre testamento. Dos 46 restantes, consta a existência de testamento em apenas cinco; em um o pároco anotou: "dizem que fez mas não o vi"; em quatro consta que "não fez testamento por morrer de repente"; em três consta apenas que "não fez testamento", e em 33 casos o pároco anotou que "não fez testamento por ser muito pobre". Assim, considerando apenas os 46 registros em que existe alguma indicação sobre testamento, o último caso equivale a $71,7 \%$ do total, e se incluirmos também os registros em que o padre afirma não haver testamento, porém sem indicar a razão, esse percentual sobe para $80,4 \%$. Isso

${ }^{29}$ MACHADO, Cacilda. A Trama das Vontades. Negros, pardos e brancos na construção da hierarquia social do Brasil escravista. Rio de Janeiro: Apicuri, 2008, cap. 4.

${ }^{30}$ MATTOS, Hebe. Escravidão e cidadania no Brasil Monárquico. Rio de Janeiro: Jorge Zahar, 2000, p. 17. 
A inserção social de negros, indíos e bastardos a partir de registros de óbitos...

significa, enfim, que o grosso da população não-branca livre do lugar vivia em condições de pobreza.

Mas, entre os brancos, a situação era pouco diferente. De um total de 279 registros de brancos maiores de 15 anos, em apenas 11 encontra-se indicação de que se tratava de pessoas de "maior qualidade" do lugar (três capitães, duas mulheres de capitães, um filho e uma filha de capitão, um tenente, um doutor e dois padres). Além disso, no conjunto de registros o pároco anotou que o falecido deixou testamento em somente 24 deles, sendo que em dois o sacerdote afirma não ter visto os testamentos e, portanto, não transcreveu a parte pia; em 20 consta que "não fez testamento por morrer apressadamente", em um registro o pároco escreveu que "não fez testamento por ser filho de família" e em outro que "não fez testamento por ser religioso de ordem mendicante". Em 24 registros o padre anotou apenas que "não fez testamento", sem indicar a razão; em 130 consta que "não fez testamento por ser muito pobre". Por fim, em 77 desses registros de óbitos não há qualquer menção a testamento, e em geral referem-se a morte de jovens. Assim, considerando apenas os registros em que existe alguma indicação sobre testamento, em $64,3 \%$ do total de casos o padre anotou a condição de pobreza do falecido. E se acrescentarmos os registros em que o padre afirma não haver testamento sem indicar a razão, esse percentual sobe para $75,7 \%$.

A violência das relações sociais e a rudeza do lugar atingiam igualmente brancos e não-brancos. Ao longo do período, foram registrados os óbitos de dez brancos e de 15 não-brancos que teriam sido assassinados (de tiro, facada ou porrete), três brancos e um não-branco morreram de mordida de cobra, um branco foi morto por um "tigre"(sic), outro por um pinheiro que lhe caiu na cabeça. Ainda dois não-brancos morreram afogados, um foi atingido por um raio, e outro sofreu um acidente não especificado pelo vigário.

Porém, somente em alguns registros de não-brancos o pároco sentiu necessidade de destacar a situação de miséria extrema ou de marginalidade. Em 1742 o sacerdote registrou a morte de um bastardo forro, que afirmou ser "pobre 
mendicante". Em 1755 foi a vez de uma jovem escrava que "morreu quando andava fugida no mato", e de uma escrava cujo marido, também escravo, de alcunha Cabeça Branca, estava fugido para Itu. Em 1756 anotou no registro de uma mulher de 70 anos, bastarda livre e casada com um indio forro, que "vivia num rancho no mato". Sobre um índio forro de 60 anos, morto em 1758, consta que "nem tinha casa de seu, só um pequeno rancho no mato, sem porta". Em 1759 anotou a morte (em dias consecutivos) de dois jovens que estavam na cadeia. Sobre um deles escreveu que era filho de mulato forro e criminoso: "o trouxeram da cadeia desta vila mas suponho que era freguês de São José". No mesmo ano morreu um homem de 40 anos, livre, casado. Afirma o pároco que "por ser criminoso e andar metido pelos matos com sua mulher e por se achar por acaso ai perto o reverendo de São José o confessou e a outros mais que morreram em uma balroada que tiveram com os oficiais de justiça". Ainda neste ano morreu uma jovem de 16 anos, de pai índio, que também "morava num rancho de palha de beira de chão". Por fim, em 1768, anotou o óbito de um homem de 35 anos, cuja esposa fora administrada. O sacerdote afirmou que "não possivel administrar o sacro viático porque sua casa tem paredes de esteira de taquara". Parece tratar-se de homens e mulheres que preferiam a frágil proteção da taquara e da palha, contra o rigoroso frio sulista, do que a submissão ao dominio senhorial.

As Constituições Primeiras do Arcebispado da Bahia, de 1707, determinavam que

nenhum defunto podia ser enterrado sem primeiro ser encomendado pelo seu pároco ou outro sacerdote de seu mandado. Além disso, deviam sempre ser acompanhados também por seus párocos, mesmo que fossem enterrados em outra freguesia. (...) O acompanhamento do defunto se fazia em procissão até a igreja onde deveria ser enterrado. A cruz da freguesia do defunto precedia as demais, exceto no caso de se alçar a da Sé. Durante a procissão havia também uma hierarquia entre as irmandades que acompanhavam o defunto. A da Misericórdia sempre precedia as demais. As demais se organizavam de acordo com sua antiguidade. Havendo dúvidas sobre a procedência das autoridades eclesiásticas, cabia ao provisor compôlas para que não houvesse desordem. ${ }^{31}$

\footnotetext{
${ }^{31}$ LOTT, Mirian Moura, op. Cit. passim

176 Revista de História Regional 15(2): 160-183, Inverno, 2010
} 
A inserção social de negros, indíos e bastardos a partir de registros de óbitos...

Eram poucos, no entanto, a receberem tantas honrarias. Das anotações do vigário da Igreja de Nossa Senhora da Luz se deduz diferenças no interior do grupo não-branco, para além daquela relacionada apenas a condição jurídica. Desses casos que relatei acima, todos os falecidos tiveram cerimônia fúnebre com apenas o essencial. Nas palavras do vigário: "foi acompanhado por mim e pela cruz da Fábrica (isto é, a cruz da freguesia) e fiz-lhe o oficio de sepultura na forma do ritual romano". Alguns nem mesmo tiveram o acompanhamento da cruz da Fábrica.

Este também foi o caso de um conjunto maior de escravos, administrados e bastardos. Dos 381 sepultamentos que observei, essa cerimônia simples foi a única reverência que se fez a pobres 256 almas, o que equivale a $67 \%$ dos nãobrancos falecidos. Em todo o período, $67,3 \%$ dos 159 escravos, $72,5 \%$ dos 91 administrados e $62,6 \%$ dos 131 bastardos livres ou forros tiveram esse triste fim.

Os escravos mais afortunados tiveram em suas cerimônias, além da cruz da Fábrica e do acompanhamento do vigário: missa de corpo presente (20 cativos, incluindo aqui os sepultamentos de ossos), mais um sacerdote acompanhando a cerimônia (três escravos), missa de corpo presente e acompanhamento da cruz do Rosário (um escravo), acompanhamento da cruz do Rosário (10 escravos), levado ao Esquife do Rosário (quatro escravos), acompanhamento da cruz e levado no esquife do Rosário (14 escravos).

Dentre os administrados, além da cerimônia básica, 25 deles também tiveram: acompanhamento de mais um sacerdote (um), missa de corpo presente (cinco), sepultamento na tumba das almas (dois), acompanhamento da cruz e sepultamento na tumba das Almas (dois), acompanhamento da cruzes das Almas e do Rosário (um), acompanhamento das cruzes das Almas e do Rosário, além de missa de corpo presente (um), acompanhamento da cruz do Rosário (três), levado no esquife do Rosário (um), acompanhamento da cruz e levado no esquife do Rosário (nove).

Além do acompanhamento do vigário e da cruz da freguesia, os bastardos e negros livres ou forros tiveram: acom- 
panhamento da cruz das Almas (um); acompanhamento da cruz e sepultura na tumba das Almas (quatro); acompanhamento da cruz das Almas, sepultura na tumba das Almas e mortalha de Nossa Senhora do Carmo (um) e outro com hábito de São Francisco; sepultura na tumba das Almas e acompanhamento das cruzes das almas, de Nossa Senhora da Luz, do Santíssimo e de todos os padres da igreja (um); sepultura na tumba da Fábrica (dois); acompanhamento da cruz do Rosário (oito); levado no esquife do Rosário (sete); acompanhamento da cruz e levado no esquife do Rosário (18).

Dentre esses negros e bastardos, cinco deixaram testamento, e tiveram satisfeitas suas vontades: um deles, um mulato, teve missa de corpo presente, acompanhamento de um segundo sacerdote e do mestre da capela, com música; o segundo, também mulato, ganhou três missas de corpo presente e mortalha branca; o seguinte, um preto forro, teve missa de corpo presente que lhe disse o padre superior da capela onde foi sepultado, e o pároco da matriz disse-lhe outra quando teve a notícia de seu falecimento. O outro preto forro teve missa e acompanhamento dos irmãos da Ordem Terceira. A bastarda Catharina da Costa Roza, filha natural de um escravista do planalto, teve sepultamento luxuoso, no esquife de Nossa Senhora do Rosário, acompanhada pelas cruzes de Nossa Senhora da Luz, das Almas, do Santíssimo e do Rosário, e usando mortalha parda.

Por um lado, essas diferenças cerimoniais sugerem que, embora negros e bastardos - e mesmo escravos ou administrados -, alguns deles eram homens e mulheres de certo cabedal, afinal, como se sabe, a satisfação dos desejos relativos aos funerais, sepultamentos e cerimônias religiosas podia ser bem dispendiosa. Valia a pena, porém. Naquele ambiente forjado por um catolicismo barroco de manifestações externas da fé, a morte era momento no qual o defunto poderia louvar os santos de devoção e salvar sua alma, ${ }^{32}$

\footnotetext{
${ }^{32}$ TRINDADE \& ANDREAZZA. Op. Cit, p. 4. Sobre religiosidade colonial ver MOTT, Luis. Cotidiano e vivência religiosa: entre a Capela e o Calundu. In: NOVAIS, Fernando (dir.) e SOUZA, Laura de Melo e (org.). História da Vida Privada no Brasil: 
A inserção social de negros, indíos e bastardos a partir de registros de óbitos...

como também oportunidade ímpar de expressão visual e pública de seu prestigio social.

O conteúdo dos testamentos dos cinco bastardos (o pároco transcreveu a parte pia nos registros de óbito) é outro testemunho desse empenho. Um deles mandou dar esmolas a cinco pobres, "em louvor das Cinco chagas de Cristo", e a três mulheres pobres, "pelo grande gosto que teve a Virgem Maria Senhora Nossa de seu sagrado parto"; uma bastarda deixou esmolas ao Santíssimo, a São Francisco das Chagas e uma maior para Nossa Senhora da Luz, além de reservar uma quantia para as obras da matriz; outro também legou uma quantia para as obras da igreja e dois deles legaram seus bens para a Irmandade da Ordem Terceira. Em outras palavras, a despeito de sua condição de homens e mulheres de menor qualidade, consideraram fundamental consolidar, após a morte, a imagem de benfeitores da igreja e da comunidade, de homens e mulheres que viveram bem integrados naquela sociedade escravista.

Por outro lado, as escolhas dos falecidos para a cerimônia de sepultamento sugerem a existência de diferenças na inserção social dos escravos, administrados e bastardos e negros livres do lugar. Considerando que os funerais de pessoas brancas tinham em geral acompanhamento das cruzes da Fábrica, das Almas e/ou de Nossa Senhora Luz, além de sepultamento na tumba das Almas, nota-se (pela lista dos sepultamentos mais elaborados) uma maior proximidade desses com alguns negros e bastardos livres e mesmo com alguns administrados, e uma maior distância social (ao menos do ponto de vista religioso) em relação aos escravos.

Os dados sobre pertencimento a irmandade do Rosário podem esclarecer mais esta questão. Tomando apenas os sepultamentos de não-brancos realizados na Igreja matriz, em nenhum dos registros entre 1731 e 1741 o pároco informou o pertencimento a Irmandade do Rosário. Entre 1741-1751 somente uma mulher (em 1750); já entre 1752 e 1761 foram

cotidiano e vida privada na América portuguesa. Vol. 1, São Paulo: Companhia das Letras, 1997. 
enterrados 37 irmãos do Rosário, e entre 1762 e 1769 mais 33. Ainda nesses dois últimos períodos foram registradas sete mortes nas quais o defunto foi levado para a igreja no esquife do Rosário, porém o pároco não anotou o pertencimento a irmandade, mas provavelmente era o caso.

Ainda conforme esses registros, principalmente as mulheres compunham a Irmandade do Rosário (49 mulheres e 29 homens). Havia membros de todas as idades (32 tinham entre 15 e 35 anos, 20 estavam ente 36 e 55 anos, e 26 com idades superiores a 56 anos) e, desde o início da existência da Irmandade, dela participavam escravos, administrados e livres não-brancos (do total, 26 eram escravos, 14 administrados e 38 livres, sendo que, destes últimos, 11 de origem indígena, oito de origem africana, e 19 sem indicação da origem).

Essa vinculação sugere, portanto, a existência de uma "elite" no interior do grupo de bastardos, pretos livres, administrados e escravos. Mas os indícios de vinculação de bastardos e administrados a Irmandade das Almas concentrados nos dois primeiros sub-periodos (alguns testadores, oito livres e três administrados entre 1738 e 1755) sugere também que, conforme aumentava a proporção de não-brancos livres na região, aumentava a separação na sociabilidade de não-brancos (mais ligados a Irmandade do Rosário) e de brancos, estes, em geral, irmãos das Almas, mas também do Santíssimo Sacramento, de Nossa Senhora da Luz e da Ordem Terceira de São Francisco das Chagas (apenas uma mulher, de 70 anos, viúva, registrada na parte reservada aos brancos do livro, foi levada a sepultura no esquife da Irmandade do Rosário).

Sabe-se que no Brasil colonial a sepultura dos cativos e dos muito pobres ficava geralmente no adro das igrejas. Por esta razão, outro indicador de conquista de certa distinção social é o local do sepultamento dos não-brancos na Igreja de Nossa Senhora da Luz de Curitiba. Nesse sentido, é interessante observar que 43 não-brancos adultos foram enterrados no adro e 26 dentro da igreja entre 1731 e 1741 ; entre 1742 e 1751 foram 47 no adro e 23 dentro da igreja.

180 Revista de História Regional 15(2): 160-183, Inverno, 2010 
A inserção social de negros, indíos e bastardos a partir de registros de óbitos...

A partir de 1751 as coisas mudaram: dessa data até 1761 , foram sepultados no adro 63 não-brancos, e 61 deles dentro da igreja; entre 1761 e 1769 apenas 21 foram enterrados no adro, e 64 dentro da igreja. Muitos desses enterramentos pós-1751 foram de irmãos do Rosário. Mas ao longo de todo o período, escravos, administrados e livres de cor que não estavam ligados a ela também garantiram sepultura no interior da matriz. Daqueles adultos enterrados no adro deduz-se, portanto, a pouca ou nenhuma chance que tiveram, ao longo da vida, de obter algum prestigio social: são 80 escravos, 46 administrados e apenas 29 livres não-brancos, junto com 17 pessoas cujas mortes foram registradas na parte reservada aos brancos.

\section{Conclusão}

Já há algum tempo a historiografia brasileira vem insistindo em caracterizar a complexidade da vida social durante o período escravista, ao buscar ir além das noções tradicionais, dicotômicas (que dividem aquela sociedade em brancos e negros, em senhores e escravos) e extremas (do escravo-mercadoria e escravo-rebelde), fazendo emergir novos atores e diferenças até mesmo no interior do cativeiro. ${ }^{33}$ Essa produção, no entanto, quase sempre enfatiza mais as possibilidades de ascensão e de visibilidade social de escravos e de egressos do cativeiro no meio urbano e, como fenômeno mais geral, sua consolidação no século final da escravidão. Para as regiões de agricultura de subsistência - em especial quando o foco é um período mais recuado -, o quadro traçado é freqüentemente o de uma pobreza indiferenciada.

Creio que este artigo pode ajudar a compor outra visão. Ele se detém em um ambiente economicamente pouco dinâmico, e em um período em que a escravidão era incon-

${ }^{33}$ A lista de trabalhos é extensa, e para obter um panorama desta produção ver, por exemplo: LARA, Silvia H. Escravidão no Brasil: balanço historiográfico. LPH, Revista de História, 3 no. 1, 1992; SCHWARTZ, Stuart. Escravos, Roceiros e Rebeldes. Bauru: Edusc, 2001; RUSSEL-WOOD, A. J. R. Escravos e libertos no Brasil Colonial. Rio de Janeiro: Civilização Brasileira, 2005. 
teste. A despeito disso, a recuperação de fragmentos de vidas - ainda que a partir das histórias de suas mortes - pôde tornar visivel o esforço (bem sucedido, eu diria) de movimentação social e conquista de prestígio dos escravos, administrados e, sobretudo, dos livres de origem indigena e africana do planalto paranaense. Também foi possivel vislumbrar (com indícios mais rarefeitos, por certo) o empenho senhorial e eclesiástico de impor limites àquela empresa, por meio da criação de um qualificativo que tendia a petrificar a marca da origem servil, que de outro modo provavelmente se perderia.

Por fim, penso que as informações sobre a população indígena, aqui expostas e analisadas, podem contribuir - modestamente - para a tarefa de revisão das noções ainda prevalecentes na historiografia brasileira: a primeira, que enfatiza a exclusão dos índios enquanto legitimos atores históricos, e a segunda, que basicamente resume a história dos índios à crônica de sua extinção. ${ }^{34}$

\section{A inserção social de negros, indios e bastardos a partir de registros de óbitos (planalto paranaense na primeira metade do século xviii)}

Cacilda Machado

Resumo: Neste artigo faço uso do primeiro livro de registros paroquiais de óbitos da Igreja de Nossa Senhora da Luz de Curitiba, a fim de conhecer a estrutura da população e o processo de inserção social de escravos, administrados e livres de cor no período inicial da colonização do planalto paranaense. Trata-se de um ambiente por então economicamente pouco dinâmico, onde em geral a historiografia não vê muita possibilidade de mobilidade social. A despeito disso, foi possivel detectar o processo de diferenciação social dos

\footnotetext{
${ }^{34}$ MONTEIRO, John (2001). Op. Cit, p. 4. 
A inserção social de negros, indíos e bastardos a partir de registros de óbitos...

escravos, administrados e, sobretudo, dos livres de origem indígena e africana do lugar, assim como o empenho dos "brancos" de impor limites àquela empresa.

Palavras-chave: Escravidão; Administração particular; Mobilidade social.

Abstract: In this article I use of the first book of parish death registers of the Nossa Senhora da Luz Church in Curitiba, in order to learn about the structure of the population and the social insertion processes for slaves, manumitted and free colored men and women in the early years of the colonization of the high lands in Paraná. It was an economic ambient not very dynamic at the time, in which historiography in general sees no possibility for social mobility. Despite this, it was possible to detect the historical process of social diferenciation for slaves, manumitted and, above all, free men of indigenous or African origem, as well as the efforts by the "whites" to impose limitations to such enterprise.

Key-Words: Slavery; Private administration; Social mobility

Recebido: 05/08/2010

Aprovado:26/10/2010 